\title{
On the relationship between locus of control and translation achievement of Iranian translation students
}

Keshmandi, Omid $\bowtie$

English Department, Imam Reza International University, Iran (omidkeshmandi@yahoo.com)

Akbari, Omid

English Department, Imam Reza International University, Iran (Omidakbari@imamreza.ac.ir)

Ghonsooly, Behzad

Department of English Language and Literature,Ferdowsi University of Mashhad, Iran (honsooly@um.ac.ir)

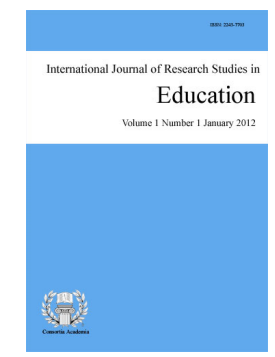

ISSN: 2243-7703 Online ISSN: 2243-7711

OPEN ACCESS

\section{Abstract}

The present study examines the relationship between Locus of control and translation achievement. The participants included 100 (73 female and 27 male) BA senior students studying English translation as their major at Imam Reza International University and Khayyam Institute of higher education. Both male and female students responded to Internal Locus of Control Index (ICI) questionnaire. They were divided into Internalizers/ Externalizers according to the scores gained in the ICI. The results of the study indicated that students' Locus of control have a positive and significant relationship with their translation achievement. Internalizers outperformed Externalizers in their translation task and it also revealed that as translation students' LOC increases, their translation achievement increases significantly. Locus of control as a psychological construct, has been the focus of attention in recent decades, therefore, the findings of current study will result in higher translation achievement of students and will help translation instructors plan better for the improvement of their students.

Keywords: locus of control; translation achievement; internalizers; externalizers 


\section{On the relationship between locus of control and translation achievement of Iranian translation students}

\section{Introduction}

Translation has a lot in common with other sciences particularly psychology. As Baker (1998, p. 4) points out translation is a separate academic discipline which, "like any young discipline, needs to draw on the findings and theories of the other related disciplines in order to develop and formulate its own methods". Apparently translation studies are a major that needs to be improved by applying different psychological factors like locus of control. Although a lot of research have been done on different realm of language learning connecting the role of some psychological factors such as Locus of control on language acquisition and in the field of psychology, lack of the relationship of this factor with translation achievement of translation students of universities is obvious. By exploring the level of LOC of a translator, it would be possible to address their training requirements in order to make them perform enthusiastically and productively.

The students of translation need to know their level of LOC because knowing this factor and the effect that it can have could help them translate better and adjust themselves to their weaknesses and strengths in translating a text. Moreover, it would be possible for translation trainers to know the strength and weakness of their trainees at the beginning of the course and get enough feedback to keep on. Locus of control, as a concept, was developed by Julian Rotter in 1954. It examines people's beliefs and the extent to which they can understand that they are in control of what happens to them. It is defined as a person's perception of control over his or her own life and how he or she copes with events and depends on different factors such as cultural, environmental, and personal variables (Rotter, 1966). Locus of control is divided into two parts; internal locus of control and external locus of control. Those with an internal LOC will view these variables as being dependent on their own abilities, effort and behavior. Those people with an external LOC view these variables as being derived from luck, chance and fate. Those who have External locus of control are believed in the external rewards which are outside of control and attribute their success to chance and environment; in contrast those who have an internal locus of control attribute their success to their own ability and effort and do not need to the external rewards for their own treatment.

According to Marks (1998) individuals with an external locus of control are less likely to change their behavior because they do not believe that this changing of their behavior can have an effect on their reinforcements. On the other hand, individuals with an internal locus of control would experience reinforcements of value as more meaningful or influential to them because they can control the reinforcements. Shapiro, Schwarts, and Austin (1996) suggest that one's beliefs about the extent of control they have regarding the fact that what happens to them is a core element in their understanding and perceiving of how they live in the world. For instance, when one fails a test, he or she experiences the need to attribute it to ability or effort or attribute it to luck and chance (influenced as Rotter posits, by their internal LOC and their external LOC). The people with internal locus of control believe that they are in charge of their own lives and activities themselves while having their output reliant upon their own personal performance (Flouri, 2006). The constructs of internality and externality were critically evaluated by Levy (1967) where he recommended that locus of control may be a function of an individual's belief system and reinforcement history.

Few researches have recently been conducted on the concept of LOC and language acquisition or teaching. Obviously, locus of control is relatively new notion in the field of Translation Studies; therefore, it is considered an essential need to be explored. Different factors can influence the translation like creative thinking and deep understanding of the text, but psychological factors like LOC can also be influential in the success of translators translating the texts. So the researcher in this study was concerned to explore the relationship between Locus of control and translation achievement. Therefore, the present study sought to address the following research 

questions:

$>$ Q1: Is there any significant relationship between translation students' Locus of control and their translation achievement?

$>\quad$ Q2: Is there any significant difference in the translation achievement of students with higher levels of Locus of control and those with lower levels of LOC?

\section{Research Null Hypotheses}

$>$ H1: There is no significant relationship between translation students' locus of control and their translation achievement.

H2: There is no significant difference in the translation achievement of students with higher levels of Locus of control and those with lower levels of Locus of control.

\section{Review of Literature}

\subsection{Locus of Control}

Several studies have been done to point out that psychological variable like Locus of control may be useful to learning and job satisfaction. The locus of control theory is a construct build on the concept of causation (Manger \& Eikeland, 2004). According to Dag (1997), locus of control is defined as a person's perception of control over his or her own life and how he or she copes with events. The Locus of control theory was developed by Rotter in 1966. According to him, LOC depends on different factors such as cultural, environmental, and personal variables. The people who have an internal locus of control do not need to the external rewards for their own treatments, in contrast, those who possess an external locus of control are believed in the external rewards which are outside of their control. Internalaizers in LOC attribute their success to their own ability and effort while Externalaizers attribute it to chance, environment, and the conditions. Individuals with internal locus of control believe that they themselves are in charge of their own lives and activities while having their output reliant upon their own personal performance (Flory, 2006, as cited in Saadat et al., 2011).

Lots of researches have been done on the concept of Locus of Control and a great number of researchers have linked the internality and externality to academic achievement. For example one of them is the examination of the effect of LOC on academic procrastination. Carden, Bryant, and Moss (2004) examined that internalizers experience lower academic procrastination, but externalizers experience higher level of academic procrastination. Ghonsooly and Elahi (2010) found that Engineering and Basic Sciences university students were internalizers and better General English (GE) learners due to their better GE scores and those learners who had lower achievement in General English(GE) were externalizers. Lonky and Reihman (1980) found that internalizers spend much time on performing learning tasks; on the other hand, externalizers do not spend much time on performing leaning tasks.

On the relationship between LOC and translation achievement, Ghonsooly and Moharer (2012) investigated the effect of Locus of Control (LOC) on translation students' achievement. The findings of this study indicated that internalizers were superior to externalizers. In other words, translation students with internal locus of control tend to be more successful in their translation tasks. A study by Rezaie Kargar et al. (2012) was done to examine the effect of teaching critical and creative thinking skills on the locus of control and psychological well-being in high school students. The findings of the research revealed that creative and critical thinking skills teaching have led to a significant decrease of locus of control and significant increase of psychological well-being. On the relationship between locus of control and ethical responses concerning academic behavior, Smith, Coates and Deis (1998) examined how the locus of control of university students can be linked to their ethical responses concerning academic-behavior items. The results indicated significant differences by the internal/external LOC 
designation.

A recent study by Saadat, Ghasemzadeh, Karami, and Soleimani(2011) indicates that there is a relationship between self-esteem and locus of control. This research aimed to study relationship between self-esteem and locus of control of Iranian University students. The results obtained from 370 students revealed that all self-esteem components had a positive and meaningful relationship with internal locus of control, although this relationship becomes negative while talking about external and chance kinds and also all grades of self-esteem components could be predicted by internal locus of control.

Danhua Wang (2005) found a significant relationship between students' learning and locus of control in web- supplemental instruction. The researcher used a qualitative multi-case study design (Merriam, 1998) to examine the learning experiences of four students in WSI through the lens of LOC. Four female college students were selected based on their scores on a LOC questionnaire. The four students were taking Instructional Systems Technology, a course required of elementary education majors in the School of Education. Data were collected throughout the semester. After analyzing the data, researcher concluded that The external focused on skills while the internal focused on concepts; the external expected more of the instructor whereas the internal took greater responsibility for self; the external did not find the web resources useful but the internal used them to facilitate learning. LOC played a role in the participants' notion of learning, sense of responsibility, and use of web resources.

In some other researches, locus of control had no effect on the given achievement. For instance, Kenneth E. Smith (2006), investigated the influence of locus of control on Student teacher beliefs about developmentally appropriate practice. The 60 participants in this study were all undergraduate elementary education majors at an urban campus of a Midwestern university. All participants were pursuing the same initial elementary education certification, but the first group had received elementary preparation while the second group had elementary plus early childhood education preparation. The results obtained after analyzing the data showed that internal locus of control orientation had no effect on the convergence of student teacher and cooperating teacher beliefs.

\subsection{Translation}

Human beings, throughout history, have made efforts to take advantage of various methods of communication with the purpose of using the knowledge of other countries and nations to keep this knowledge for future generations; therefore, the language has been used to satisfy the very need of communication. Nowadays, communication among many nations with different languages is possible through translation. To evaluate a translation work, experts in the fields of translation try to come up with certain criteria whose application would lead to better assessment of translation work and more comprehensive feedback for observing better translation. Therefore, such assessment area is 'one where a more expert writer or a marker of translation examination or a receiver of a professional translation addresses a less expert reader or usually a candidate for examination or a junior professional translator (Munday, 2008). There are different methods of assessment for students' translation used by teachers of translation. On the criteria related to improvement of translation assessment, Waddington (1999-2001) examined two kinds of methods typically used at European universities based on error analysis and those based on a holistic approach. In his paper, four methods were discussed as follow:

Method A which is based on error analysis and possible mistakes and are grouped under the following headings:

$>\quad$ Inappropriate renderings which affect the understanding of the source text; these are divided into eight categories: contresens, faux sens, nonsens, addition, omission, unresolved extralinguistic references, loss of meaning, and inappropriate linguistic variation (register, style, dialect, etc.).

$>$ Inappropriate renderings which affect expression in the target language; these are divided into five 
categories: spelling, grammar, lexical items, text and style.

$>\quad$ Inadequate renderings which affect the transmission of either the main function or secondary functions of the source text."

In each of the categories a distinction is made between serious errors ( -2 points) and minor errors $(-1$ point). There is a fourth category which describes the plus points to be awarded for good (+1 point) or exceptionally good solutions ( +2 points) to translation problems.

Method B is also based on error analysis and was designed to measure the negative effect of errors on the overall quality of the translations. The corrector first has to determine whether each mistake is a translation mistake or just a language mistake; this is done by deciding whether or not the mistake affects the transfer of meaning from the source to the target text: if it does not, it is a language error (and is penalized with -1 point); if it does, it is a translation error (and is penalized with -2 points).

Method C in Waddington's methods of assessment is a holistic method of assessment. In this method, $0-$ 10 is considered for the corrector to award the higher mark to the candidate who fully meets the requirements of a particular level and the lower mark to the candidate who falls between two levels but is closer to the upper one. And the last method introduced by Waddington consists of combining error analysis Method B and holistic Method C.

\section{Methodology}

\subsection{Participants}

This study was done in Mashhad, Iran. The participants of the study consisted of 100 senior translation students of Imam Reza International University and Khayyam Institutes of Higher Education. All of them were required to have passed the basic courses in translation field namely "Principles and Methodology of Translation" and "Theories of Translation". The participants were both male (27\%) and female (73\%). They were given the locus of control and according to this factor they were classified into Internalizers and externalizers.

\subsection{Instrumentation}

The LOC instrument - Internal Locus of Control Index (ICI) Questionnaire designed by Duttweiler in 1984 is a locus of control scale used in this study as a more reliable alternative to the most commonly used locus of control scale, The Rotter I-E scale (1966). Duttweiler designed this questionnaire to measure where a person tries to get reinforcement. ICI consists of 28 items and choices on a 5-point Likert-type scale range from "rarely: less than $10 \%$ of the time" to "usually: more than $90 \%$ of the time" and each item is scored on the 5-point Likert scale with responses of rarely, occasionally, sometimes, frequently, and usually. The scores range between 28 and 140 and those who get 127 and more are grouped as Internal Locus of control and those who get less than 127 are grouped as External Locus of control (Ghonsooly \& Moharer, 2012).

Rendering Text - In the first step, a general text was selected by the researcher, the supervisor and by an examiner. The text was taken from a book named "Techniques of Advanced Translation" by Dr. Alaeddin Pazargadi which was published in spring 1378. Then text was examined by the researcher and supervisor and also it was examined by an examiner in the given field and since the text is about Language communication and it includes some aspects of Cognitive style, it could be a good choice for the translation task. Therefore after being examined, it was chosen for the related purpose. 


\subsection{Data collection}

In the first step, after getting permission from the instructors, the researcher visited the classes to administer the Locus of control questionnaire. First, they were introduced to the Internal Index questionnaire .Then the students were asked to translate the general text from English to Persian. While the participants were answering the questionnaire, they were served juice and cookies to help them focus better on the questionnaire items. Students rated the LOC questionnaire on a 5-point Likert scale with responses of rarely, occasionally, sometimes, frequently, and usually. The highly internal respondents are expected to answer half at the usually end of the scale and the other half at the rarely end of the scale.

\subsection{Data Analysis}

In order to answer the first research question, the Pearson Correlation formula was used. And to answer the second research question an independent sample t-test was used. The LOC questionnaire is on a 5-point Likert scale with responses of rarely, occasionally, sometimes, frequently, and usually. The 'rarely' is scored as 5 points on items 1, 2, 4, 6, 11, 14, 17, 19, 22, 23, 24, 26, and 27 for the rest of items the "usually" response is scored as 5 points (Ghonsooly \& Moharer, 2012). This produces a possible range of scores from 28 to 140 with higher scores reflecting higher internal locus of control. Moreover, the rendering text was scored by the researcher and an examiner with the degree of MA in translation. They scored the text for naturalness and accuracy and then they had a mean score for both of the given items. The text was scored based on Waddington's model of translation assessment (2001).

\section{Results}

In Table 1, Minimum, Maximum, Mean and Standard Deviation of the variables of students' translation achievement, Locus of control is presented. Minimum, Maximum, Mean and Standard Deviation of the variables for students' translation achievement are 1, 8, 3.92, and 1.3 respectively. Minimum, Maximum, Mean and Standard Deviation of the variables of students' Locus of Control are 70, 132, 98.02, and 16.5 respectively.

Table 1

Descriptive Statistics variables

\begin{tabular}{lccccc}
\hline \multicolumn{1}{c}{ Treatment group } & $\mathrm{N}$ & Minimum & Maximum & Mean & Std. Deviation \\
\hline translation achievement & 100 & 1.00 & 8.00 & 3.92 & 1.3 \\
Locus of Control & 100 & 70.00 & 132.00 & 98.02 & 16.5 \\
\hline
\end{tabular}

To test the normality of the variables, Kolmogorov-Smirnov Test was used in the study to test if the variables have the level of normal distribution. If the variables are normal, the parametric tests will be used and if not, nonparametric tests will be useful for the given purpose. The results of Kolmogorov-Smirnov Test are shown in Table 2.

\section{Table 2}

One-Sample Kolmogorov-Smirnov Test

\begin{tabular}{lcc}
\hline & Translation achievement & Locus of Control \\
\hline $\mathrm{N}$ & 100 & 100 \\
Kolmogorov-Smirnov Z & 1.078 & 1.085 \\
Asymp. Sig. (2-tailed) & .14 & .189 \\
\hline
\end{tabular}

As can be seen in Table 2, since the meaningful level of the test for all the variables is more than 0.05, the normality assuming of the variables is accepted and all the variables fit the normal distribution. Therefore, parametric tests can be used for testing the hypotheses. The first research questions deals with the relationship 
On the relationship between locus of control and translation achievement of Iranian translation students between translation students' Locus of control and their translation achievement. To test such relationship Pearson Correlation Test was used.

Table 3

Correlations between Translation achievement and Locus of control

\begin{tabular}{llc}
\hline & & Locus of Control \\
\hline \multirow{3}{*}{ Translation achievement } & Pearson Correlation & $.498^{*}$ \\
& Sig. (2-tailed) & .000 \\
& $\mathrm{~N}$ & 100 \\
\hline
\end{tabular}

Note. *Correlation is significant at the 0.05 level (2-tailed).

As it can be seen in Table 3, the meaningful level of Pearson Correlation Test between translation student's Locus of control and his/her translation achievement is 0.000 that is less than 0.05 ; therefore, with $95 \%$ of certainty $\mathrm{HO}$ is rejected and it can be said that there is a significant relationship between translation student's Locus of control and his/her translation achievement and on the basis of positive Pearson correlation coefficient (0.498), there is a linear equation between variables. It means as translation student's LOC increases, his/her translation achievement increases significantly. $(r=0.498$, sig $<0.05)$.

An Independent sample t-test is used to test whether if there are any significant differences in translation achievement of students with higher levels of Locus of control compared to those with lower levels of LOC.

Table 4

Group Statistics and t-test for Equality of Means

\begin{tabular}{|c|c|c|c|c|c|c|c|c|c|}
\hline & \multicolumn{2}{|c|}{$\begin{array}{c}\text { Levene's Test for } \\
\text { Equality of Variances }\end{array}$} & \multicolumn{7}{|c|}{ t-test for Equality of Means } \\
\hline & $\mathrm{F}$ & Sig. & group & $\mathrm{N}$ & Mean & $\begin{array}{c}\text { Std. } \\
\text { Deviation } \\
\end{array}$ & $\begin{array}{c}\text { Mean } \\
\text { Difference }\end{array}$ & $\mathrm{t}$ & Sig. \\
\hline $\begin{array}{l}\text { Equal variances } \\
\text { assumed }\end{array}$ & \multirow{2}{*}{2.071} & \multirow{2}{*}{0.153} & High & 14 & 5.7857 & .89 & \multirow{2}{*}{2.16} & \multirow{2}{*}{6.95} & \multirow{2}{*}{.000} \\
\hline $\begin{array}{l}\text { Equal variances not } \\
\text { assumed }\end{array}$ & & & Low & 86 & 3.6163 & 1.1 & & & \\
\hline
\end{tabular}

Note. *Significant at the 0.05 level (2-tailed).

As can be seen in Table 4, the mean scores related to translation achievement of students with higher levels of Locus of control and those with lower levels of Locus of control are 5.7857and 3.6163 respectively. The meaningful level of the test is less than 0.05 ; therefore, with $95 \%$ of certainty $\mathrm{H} 0$ is rejected and it mean that there is a significant difference between the translation achievement of students with higher levels of Locus of control and those with lower levels of Locus of control. Based on the mean score of the variables, it can be said that the grade of translation achievement of students with higher level of LOC compared to translation achievement of students with lower level of LOC, is more and bigger.

\section{Discussion and Conclusion}

The current study was done to examine the relationship between Locus of control and Translation achievement. The results of the research questions indicated that the translation students who believe in their own way of translation and not fate or chance, performed better and are more likely to succeed and it also supported the fact that translators who can perceives information analytically and are able to analyze and isolate relevant details are more successful in task of translation. The findings of this study also illustrated a significant difference in translation achievement of those who believe in their own ability to succeed (Internalizers) compared to those who believe in external clues in order to succeed (Externalizers). It was found that Internal (LOC) outperformed external(LOC) with regard to translation achievement. A lot of researches have been done 
Keshmandi, O., Akbari, O., \& Ghonsooly, B.

on the relationship between academic achievement and education or language learning. So it is rather difficult to link the findings of current study with the related literature. However, it is tried to consider translation achievement as a construct that is similar to academic achievement in general (Ghonsooly-Moharer, 2012).

\subsection{Implications}

The present study provides implications for translation teachers and instructors and also translation students .In the related literature on Locus of control, it is tried to link a strong association between translation achievement in particular and LOC and academic achievement in general. The findings of this study for internality and externality is in agreement with Ghonsooly and Elahi (2010), Lonky and Reihman (1980), Ghonsooly and Moharer (2012), Saadat, Ghasemzadeh, Karami, and Soleimani (2011), Owie (1983), Smith et al., (1998), Danhua Wang (2005), Mesgar et al. (2014), and Lee(2013). Ghonsooly and Moharer (2012) concluded that translation students with internal locus of control tend to be more successful in their translation tasks. Therefore, it is essential for translation teachers and instructors to make use of psychological instruments like LOC to improve their learners' motivation and also for students to improve their weaknesses in translating a text. Morris and Messer (1978) also found that internalizers have more academic task persistence (Ghonsooly \& Moharer, 2012). Therefore, translation students with Internal Locus of control are more persistent in their translation tasks. Saadat, Ghasemzadeh, Karami, and Soleimani (2011), indicated that self-esteem components had a positive and meaningful relationship with internal locus of control.

Consequently those with internal locus of control do not need to the external rewards for their own treatments. Ikponmwosa Owie (1983) found that internally oriented students appeared to attain higher levels of achievement and the externally oriented students were found to be more comfortable under conditions. It means that Externalaizers attribute success to chance, environment, and the conditions. Ghonsooly and Elahi (2010) concluded that locus of control had a positive correlation with their L2 reading and writing achievement and internally oriented students were more likely to succeed in L2 writing and reading. So as a result, those who believe they can influence their own learning are more likely to succeed. In some other parts of related literature, there is a contrast between the results of current study for Locus of control and the given studies. For example, Benson and Yeany(1986), indicated that the locus of control of the students was shown to be of minimal importance in determining student achievement which is in disagreement with the findings of current study. And In another similar study by Kenneth E. Smith (2006), it was found that internal locus of control orientation had no effect on the convergence of student teacher and cooperating teacher beliefs which is also in contrast with the current research that Internal locus of control had an important and effective role on the given achievement.

In conclusion, this study began with the goal of examining the relationship between Locus of control and Translation achievement and the results demonstrated a positive relationship between Locus of control and translation achievement of translation students. On the other hand, it means as translation student's LOC increases, his/her translation achievement increases significantly. In general, translation instructors who are familiar with the concepts of internality/externality of Locus of control can help students in their translation task and student can plan better for their translation process.

\subsection{Suggestions for further research}

In this study a general English text was used as an instrument to measure the translation achievement. The study can be replicated using other genre of translation. And also Locus of control was linked to translation achievements of students in general. So it can be linked to more specified kinds of translation like literary translation in the future studies. The current study involved two universities and is based on the data from Imam Reza University and Khayyam Higher education Institute so, the sample was not very big and the findings cannot be generalized to all other Universities and Higher education Institutes. So for bigger sample it can include more universities and institutes. 


\section{References}

Baker, M. (1998). The Routledge encyclopedia of translation studies. London and New York: Routledge. http://dx.doi.org/10.4324/9780203359792

Benson, J. S., \& Yeany, R. H. (1986). Generalizability of diagnostic-prescriptive teaching strategies across student locus of control and multiple instructional units. Journal of Research in Science Teaching, 23(2), 113-120. http://dx.doi.org/10.1002/tea.3660230204

Carden, R., Bryant, C., \& Moss, R. (2004). Locus of control, test anxiety, academic procrastination, and achievement among college students. Psychological Reports, 95(2), 581-582. http://dx.doi.org/10.2466/pr0.95.2.581-582

Duttweiler, P. C. (1984). The internal control index: A newly developed measure of locus of control. Education and Psychological Measurement, 44, 209-221. http://dx.doi.org/10.1177/0013164484442004

Flouri, E. (2006). Parental interest in children education. British journal of Educational Psychology, 76, 41-55. http://dx.doi.org/10.1348/000709905X52508

Ghonsooly, B., \& Elahi, M. (2010). Validating locus of control questionnaire and examining its relation to general English achievement. Journal of Teaching Language Skills, 2(1), 117-144.

Ghonsooly, B., \& Moharer, A. (2012). Examining the relationship between translation students, locus of control and their translation achievement. International Journal of Linguistics, 4(2), 244-256. http://dx.doi.org/10.5296/ijl.v4i2.1796

Lonky, E., \& Reihman, J. (1980). Cognitive evaluation theory, locus of control and positive verbal feedback. Paper presented at the American Psychological Association, Montreal, Canada.

Lee, H. W. (2013). Locus of control, socialization, and organizational identification. Management Decision, 51(5), 1047-1055. http://dx.doi.org/10.1108/MD-11-2012-0814

Mesgar, M., Nadzrah, A. B., \& Zaini, A. (2014). Online metacognitive and interactional strategy use: Iranian students' internal locus of control. International Conference on knowledge-innovation-excellence: Synergy in language research and practice. Procedia - Social and Behavioral Sciences, 118, 288-295. http://dx.doi.org/10.1016/j.sbspro.2014.02.039

Munday, J. (2008). Introducing translation studies (2nd ed.). New York: Routledge.

Owie, I. (1983). Locus of control, instructional mode and students' achievement. Instructional Science, 12, 383-388. http://dx.doi.org/10.1007/BF00154129

Pazargadi, A. (1996). The book of techniques of advanced translation. Ghazvin: Obeid Zakani.

Rotter, J. B. (1966). Generalized expectancies of internal versus external control of reinforcements. Psychological Monographs, 80(609). http://dx.doi.org/10.1037/h0092976

Rotter, J. B. (1982). The development and application of social learning theory: Selected papers. New York: Praeger.

Smith, K. E. (1997). Student teachers beliefs about developmentally appropriate practice: Pattern, stability, and the influence of locus of control. Early Childhood Research Quarterly, 12, 221-243. http://dx.doi.org/10.1016/S0885-2006(97)90015-6

Smith, A. J., Coates, D., \& Deis, D.R. (1998). Are ethical responses linked to Locus of control? Teaching Business Ethics, 2, 249-260. http://dx.doi.org/10.1023/A:1009750101087

Saadat, M., Ghasemzadeh, A., Karami, S., \& Soleimani, M. (2012). Relationship between self-esteem and locus of control in Iranian University students. Procedia - Social and Behavioral Sciences, 31, 530-535. http://dx.doi.org/10.1016/j.sbspro.2011.12.099

Waddington, C. (2001). Different methods of evaluating student translations: The question of validity. Translators' Journal, 46(2), 311-325. http://dx.doi.org/10.7202/004583ar

Wang, D. (2005). Students' learning and locus of control in web-supplemental instruction. Innovative Higher Education, 30(1), 67-82. http://dx.doi.org/10.1007/s10755-005-3299-x 


\section{Appendices}

\section{Appendix A}

The purpose of language is communication. Until it is used for communicating, it is not language but only parroting; yet many of the textbooks written by some of America's most reputable linguists make little or no provision for communication. There are manipulative exercises galore, but the student is never allowed to have an idea he wishes to convey, to find within himself the necessary words and the grammatical devices, and to express his thought. Occasionally, at the end of a lesson, there is a suggestion such as: 'the ingenious will know how to provide opportunities for his students to use in a conversational situation the constructions already learned. 'Needless to say, this amounts to abandoning the teacher precisely at the moment he most needs help. The most significant trend, then, in methods of teaching English as a second language may well prove to be the attempt to assign to communication its proper role in the classroom. This trend is not one of the sensational new developments, but it has given rise in the last year or two to the production of small numbers of effective textbooks for use at various levels of instruction. 


\section{Appendix B}

Please read each statement. Where there is a blank, decide what your normal or usual attitude, feeling, or behavior would be:

$\mathrm{A}=$ Rarely (less than $10 \%$ of the time)

$\mathrm{B}=$ Occasionally (about $30 \%$ of the time)

$\mathrm{C}=$ Sometimes (about half the time)

$\mathrm{D}=$ Frequently (about $70 \%$ of the time)

$\mathrm{E}=$ Usually (more than $90 \%$ of the time)

Of course, there are always unusual situations, in which this would not be the case, but think of what you would do or feel in most normal situations.

Write the letter that describes your usual attitude or behavior in the space provided on the response sheet.

1. When faced with a problem I try to forget.

2. I__ need frequent encouragement from others for me to keep working at a difficult task.

3. I_ like jobs where I can make decisions and be responsible for my own work.

4. I__ change my opinion when someone I admire disagrees with me.

5. If I want something I____ work hard to get it.

6. I___ prefer to learn the facts about something from someone else rather than having to dig them out for myself.

7. I___ will accept jobs that require me to supervise others.

8. I ___ have a hard time saying "no" when someone tries to sell me something.

9. I _ like to have a say in any decisions made by any group I' $m$ in.

10. I___ consider the different sides of an issue before making any decisions.

11. What other people think has a great influence on my behavior.

12. Whenever something good happens to me I

13. I ___ enjoy being in a position of leadership.

14. I I__ need someone else to praise my work before I am satisfied with what I've done.

15. I I__ am sure enough of my opinions to try and influence others.

16. When something is going to affect me I____ learn as much about it as I can.

17. I __ decide to do things on the spur of the moment.

18. For me, knowing I've done something well is ___ more important than being praised by some else.

19. I I__ let other peoples ${ }^{e e}$ demands keep me from doing things I want to do.

20. I___ stick to my opinions when someone disagrees with me.

21. I___ do what I feel like doing not what other people think I ought to do.

22. I___ get discouraged when doing something that takes a long time to achieve results.

23. When part of a group I

24. When I have a problem I prefer to let other people make all the decisions.

enjoy trying to do difficult tasks more than I enjoy trying to do easy tasks.

26. I__ prefer situations where I can depend on someone else's ability rather than just my own.

27. Having someone important tell me I did a good job is ___ more important to me than feeling I've done a good job.

28. When I'm involved in something I someone else is in charge. try to find out all I can about what is going on even when 
Keshmandi, O., Akbari, O., \& Ghonsooly, B. 